\title{
Strain-level characterization of nonstarter lactic acid bacteria in Norvegia cheese by high-resolution melt analysis
}

\author{
D. Porcellato, ${ }^{1}$ H. M. Østlie, K. H. Liland, K. Rudi, T. Isaksson, and S. B. Skeie \\ Department of Chemistry, Biotechnology and Food Science, Norwegian University of Life Science, PO Box 5003, N-1432 Aas, Norway
}

\section{ABSTRACT}

The nonstarter lactic acid bacteria (NSLAB) constitute an important microbial group found during cheese ripening and they are thought to be fundamental to the quality of cheese. Rapid and accurate diagnostic tests for NSLAB are important for cheese quality control and in understanding the cheese ripening process. Here, we present a novel rapid approach for strain-level characterization through combined 16S rRNA gene and repetitive sequence-based high-resolution melt analysis (HRM). The approach was demonstrated through the characterization of 94 isolates from Norvegia, a Goudatype cheese. The HRM profiles of the V1 and V3 variable regions of the $16 \mathrm{~S}$ rRNA gene of the isolates were compared with the HRM profiles of 13 reference strains. The HRM profile comparison of the $\mathrm{V} 1$ and $\mathrm{V} 3$ regions of the $16 \mathrm{~S}$ rRNA gene allowed discrimination of isolates and reference strains. Among the cheese isolates, Lactobacillus casei/paracasei (62 isolates) and Lactobacillus plantarum/Lactobacillus pentosus (27 isolates) were the dominant species, whereas Lactobacillus curvatus/ Lactobacillus sakei were found occasionally (5 isolates). The HRM profiling of repetitive sequence-based PCR using the $(\mathrm{GTG})_{5}$ primer was developed for strain-level characterization. The clustering analysis of the HRM profiles showed high discriminatory power, similar to that of cluster analysis based on the gel method. In conclusion, the HRM approach in this study may be applied as a fast, accurate, and reproducible method for characterization of the NSLAB microflora in cheese and may be applicable to other microbial environments following selective plate culturing.

Key words: high-resolution melt analysis, nonstarter lactic acid bacteria, repetitive sequence-based PCR, $(\mathrm{GTG})_{5}$ primer

Received January 26, 2012.

Accepted May 10, 2012.

${ }^{1}$ Corresponding author: davide.porcellato@umb.no

\section{INTRODUCTION}

The lactic acid bacteria (LAB) constitute a group of gram-positive bacteria with fermentative metabolism. Lactic acid is the major metabolic product produced during the fermentation of carbohydrates. Of this group, the nonstarter LAB (NSLAB) have been studied for their importance in cheese manufacturing. The NSLAB tend to dominate the microbiota in the later stages of cheese ripening, where they may reach $\log 6$ to $7 \mathrm{cfu} / \mathrm{g}$, and they may contribute positively to cheese flavor (Fox et al., 1998; Ardö, 2006; Settanni and Moschetti, 2010). The NSLAB are not part of the starter culture and they may come from the milk or from environmental contamination during cheese manufacturing. The most common NSLAB group is mesophilic lactobacilli, although Pediococcus and Enterococcus spp. may also be found. Several species of mesophilic lactobacilli are isolated from cheese and, of these, Lactobacillus casei/ paracasei, Lactobacillus plantarum, and Lactobacillus curvatus are the most common species found in Cheddar and Dutch-type cheese made from pasteurized or microfiltered milk (Jordan and Cogan, 1993; Beresford et al., 2001; Østlie et al., 2004, 2005).

Characterization of Lactobacillus isolates in cheese by phenotypic and biochemical methods is laborious, time consuming, and often inaccurate. In contrast, molecular methods are more rapid, reliable, and reproducible and have greater sensitivity. Sequence-based methods are more repeatable compared with gel-based methods (Foxman et al., 2005). High-resolution melt analysis (HRM) is a recently developed post-PCR technique used to study DNA melting kinetics. With strict control of the temperature increase (sensitivity up to $0.01^{\circ} \mathrm{C} / \mathrm{s}$ ), fluorescence decrease of a saturated double-stranded DNA binding dye is monitored. The melting temperature $\left(\mathbf{T}_{\mathbf{m}}\right)$ and curve shape are influenced by amplicon length, sequence, and GC content of the double strand, allowing comparison and discrimination of samples (Price et al., 2007; Reed et al., 2007; Patel, 2009).

Variable regions of the $16 \mathrm{~S}$ ribosomal RNA gene are used for identification of species and fingerprinting analysis of communities by different methods as 
Table 1. Lactic acid bacteria strains used as reference for high-resolution melt analysis and repetitive sequence-based PCR fingerprinting

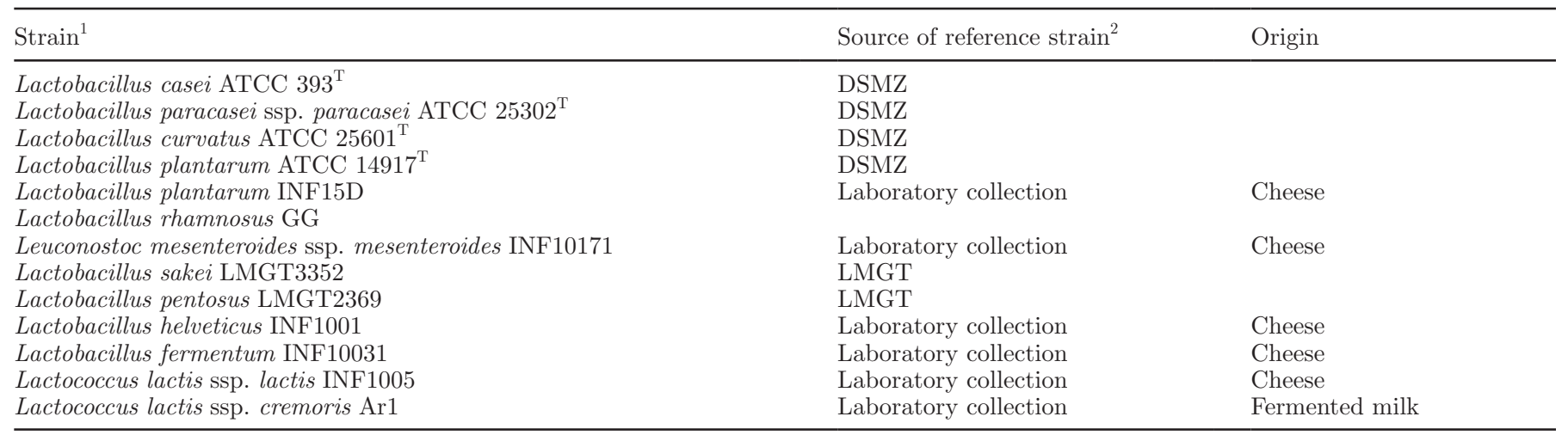

${ }^{1}$ The first 5 strains listed were used as reference strains for fingerprinting analysis; ${ }^{\mathrm{T}}=$ type strain.

${ }^{2}$ DSMZ = Deutsche Sammlung von Mikroorganismen und Zellkulturen (Braunschweig, Germany); LMGT = Laboratory of Microbial Gene Technology, Norwegian University of Life Science (Norway).

denaturing gradient gel electrophoresis (DGGE) and temperature gradient gel electrophoresis (TGGE), due to their variability between closely related species and subspecies. The 16S rRNA V1 and V3 regions have been successfully utilized to discriminate LAB found in different food environments (Ercolini et al., 2001; Ercolini, 2004; Lorbeg et al., 2009).

Among the different typing methods, amplification of repetitive sequence-based PCR (rep-PCR) has been used to differentiate LAB at the species, subspecies, and potential strain level. The use of the (GTG) primer has been shown to be the most discriminatory primer providing a complex pattern compared with other primers (Gevers et al., 2001; Adiguzel et al., 2009; Singh et al., 2009).

The aim of this study was the strain-level characterization of NSLAB isolates from Norvegia cheese through comparison of the traditional methods (16S sequencing and rep-PCR) and HRM analysis. The HRM was based on the profiling analysis of the V1 and V3 regions of the $16 \mathrm{~S}$ rRNA gene and fingerprinting analysis by rep-PCR.

\section{MATERIALS AND METHODS}

\section{Bacteria Strains and Cultivation}

At the research organization SINTEF (www. SINTEF.com), bacteria isolates (86) were picked from agar plates incubated with cheese slurries from cheese made at 4 dairies in Norway. Sampling of the cheese was done by the dairy company TINE SA Research Center (Stavanger, Norway). The bacteria were plated on de Man, Rogosa, and Sharpe agar (MRS; Difco Laboratories, Detroit, MI) incubated at $30^{\circ} \mathrm{C}$ for 3 to 4 d. Lactic acid bacterial colonies were purified by successive subculturing on MRS agar, giving 94 pure cheese isolates. Strains used as reference and their origin are shown in Table 1. Reference strains and pure cheese isolates (94) were stored at $-80^{\circ} \mathrm{C}$ in broth supplemented with $15 \%$ (vol/vol) glycerol; MRS (Difco) was used for Lactobacillus and Leuconostoc and M17 (Merck, Darmstadt, Germany) for Lactococcus. Working isolates and reference strains were prepared from frozen cultures by 1 to 2 consecutive transfers of the Lactobacillus and Leuconostoc in MRS broth (Difco) and Lactococcus in M17 (Merck) and incubated overnight at $30^{\circ} \mathrm{C}$.

\section{S rRNA Gene Sequencing of Cheese Isolates}

The universal primers $11 \mathrm{~F}$ (5'-TAACACATGCAAGTCGAACG-3') and 5R (5'-GGTTACCTTGTTACGACTT-3') (Escherichia coli positions 50-70 and 1492-1510, respectively) were used for amplification of a 1,460-bp DNA fragment of the $16 \mathrm{~S}$ rRNA gene. The PCR was accomplished using DyNazyme II DNA polymerase (Finnzymes, Vantaa, Finland). Thermocycling conditions were as follows: $2 \mathrm{~min}$ at $94^{\circ} \mathrm{C}$, followed by 30 cycles of $30 \mathrm{~s}$ at $94^{\circ} \mathrm{C}, 30 \mathrm{~s}$ at $56^{\circ} \mathrm{C}$, and $1.5 \mathrm{~min}$ at $72^{\circ} \mathrm{C}$, followed by $10 \mathrm{~min}$ at $72^{\circ} \mathrm{C}$. The PCR fragments were purified using the NucleoSpin extract II PCR clean-up kit (Macherey-Nagel GmbH \& Co. KG, Düren, Germany) according to the procedure recommended by the manufacturer. Automated DNA sequencing was provided by GATC Biotech AG (Konstanz, Germany) using the universal primers $11 \mathrm{~F}$ and $5 \mathrm{R}$. Sequences were edited using BioEdit software (Ibis Biosciences, Carlsbad, CA) and were compared in GenBank using the BLAST algorithm (http://www.ncbi.nlm.nih.gov/ blast/). 
Table 2. Reference strains and melting temperature $\left(\mathrm{T}_{\mathrm{m}}\right.$; mean $\left.\pm \mathrm{SD}\right)$ of the amplified PCR product from the $\mathrm{V} 1$ and V3 regions of the $16 \mathrm{~S}$ rRNA gene

\begin{tabular}{lcc}
\hline & \multicolumn{2}{c}{$\mathrm{T}_{\mathrm{m}}\left({ }^{\circ} \mathrm{C}\right)$} \\
\cline { 2 - 3 } Reference strain & $\mathrm{V} 1$ & $\mathrm{~V} 3$ \\
\hline Lactobacillus casei ATCC 393 & $84.65 \pm 0.04$ & $86.83 \pm 0.04$ \\
Lactobacillus paracasei ssp. paracasei ATCC 25302 & $84.55 \pm 0.04$ & $86.73 \pm 0.03$ \\
Lactobacillus curvatus ATCC 25601 & $82.41 \pm 0.06$ & $84.37 \pm 0.03$ \\
Lactobacillus plantarum ATCC 14917 & $81.77 \pm 0.03$ & $83.86 \pm 0.04$ \\
Lactobacillus rhamnosus GG & $81.30 \pm 0.05$ & $86.73 \pm 0.03$ \\
Leuconostoc mesenteroides ssp. mesenteroides INF 10171 & $84.87 \pm 0.04$ & $85.01 \pm 0.04$ \\
Lactobacillus sakei LMGT 3352 & $82.63 \pm 0.03$ & $84.35 \pm 0.05$ \\
Lactobacillus pentosus LMGT 2369 & $81.81 \pm 0.09$ & $83.97 \pm 0.05$ \\
Lactobacillus helveticus INF1001 & $86.19 \pm 0.07$ & $84.71 \pm 0.02$ \\
Lactobacillus fermentum INF 10031 & $82.05 \pm 0.05$ & $84.65 \pm 0.07$ \\
Lactococcus lactis ssp. lactis INF 1005 & $84.34 \pm 0.03$ & $85.64 \pm 0.03$ \\
Lactococcus lactis ssp. cremoris Ar1 & $82.90 \pm 0.08$ & $85.65 \pm 0.03$ \\
\hline
\end{tabular}

\section{HRM Analysis of Variable Regions}

Total DNA was extracted from $1.5 \mathrm{~mL}$ of overnight grown bacteria in MRS (Lactobacillus, Leuconostoc) or M17 (Lactococcus) medium at $30^{\circ} \mathrm{C}$ by GelElute Bacterial Genomic DNA kit (Sigma-Aldrich, St. Louis, MO) according to the manufacturer's instructions. The V3 and V1 regions of the 16s rRNA gene were amplified using the primer pairs PRBA338f-PRUN518r (Øvreås et al., 1997) and P1V1-P2V1 (Klijn et al., 1991), respectively. The PCR and HRM were performed in a 96-multiwell LightCycler 480 Real-Time instrument (Roche, Mannheim, Germany). The PCR mixture contained 1× LightCycler 480 HRM MasterMix, (Roche), a final concentration of $0.4 \mu M$ of each primer (Invitrogen Ltd., Paisley, UK), a final concentration of $2 \mathrm{mM}$ $\mathrm{MgCl}_{2}$, and $10 \mathrm{ng}$ of total DNA. The PCR amplification was conducted as follows: 1 cycle of denaturation at $95^{\circ} \mathrm{C}$ for $5 \mathrm{~min}, 30$ cycles consisting of denaturation at $95^{\circ} \mathrm{C}$ for $30 \mathrm{~s}$, annealing at $53^{\circ} \mathrm{C}$ (for the $\mathrm{V} 3$ region) and at $52^{\circ} \mathrm{C}$ (for the $\mathrm{V} 1$ region) for $30 \mathrm{~s}$, and elongation at $72^{\circ} \mathrm{C}$ for $1 \mathrm{~min}$. The HRM was performed from 65 to $95^{\circ} \mathrm{C}$ with an increase of $0.01^{\circ} \mathrm{C} / \mathrm{s}$ and 50 measurements per $1^{\circ} \mathrm{C}$. The melting peak of the PCR product was used to check amplification and primerdimer formation. The maximum of the first derivative of the PCR melting peak was used to identify the $\mathrm{T}_{\mathrm{m}}$ of the PCR amplicons. The gene scanning analysis of the HRM profiles was performed by LightCycler 480 software version 1.5 (Roche). The amplified product of Lb. casei ATCC393, Lb. paracasei ATCC25302, Lb. curvatus ATCC25601, Lb. plantarum ATCC14917, and $L b$. plantarum INF15D were checked on a $1.5 \%$ (wt/vol) agarose gel stained with $0.5 \mathrm{mg} / \mathrm{L}$ ethidium bromide and visualized under UV light (Gel Doc 1000, Bio-Rad, Hercules, CA). Reproducibility of the $\mathrm{T}_{\mathrm{m}}$ value was determined by performing triplicate runs of the reference strains listed in Table 2.

\section{Fingerprinting Methods}

All cheese isolates (94) and 5 of the selected reference strains (Table 1) were subjected to rep-PCR with a single oligonucleotide primer, (GTG) 5 (5'-GTGGTGGTGGTGGTG-3'; Versalovic et al., 1994). A 96-multiwell LightCycler 480 Real-Time instrument (Roche) was used for amplification. The PCR mixture contained $1 \times$ LightCycler 480 HRM MasterMix (Roche), $2 \mu \mathrm{mol}$ of (GTG) $)_{5}$ primer (Invitrogen), $2 \mathrm{mM} \mathrm{MgCl}{ }_{2}$, and $10 \mathrm{ng}$ of DNA in a final volume of $20 \mu \mathrm{L}$. The PCR was performed as follows: initial denaturation at $95^{\circ} \mathrm{C}$ for $7 \mathrm{~min}, 30$ cycles consisting of denaturation at $95^{\circ} \mathrm{C}$ for $30 \mathrm{~s}$, annealing at $40^{\circ} \mathrm{C}$ for $1 \mathrm{~min}$, and elongation at $72^{\circ} \mathrm{C}$ for $3 \mathrm{~min}$. The HRM analysis was performed as described above. The 5 reference strains were analyzed in duplicate for 10 independent runs to check the repeatability of the HRM profile using the same extracted DNA. Five microliters of the PCR product was loaded on a $1.5 \%$ (wt/vol) agarose gel (15 $\times 25 \mathrm{~cm}$ ), and the gel was run for $4.5 \mathrm{~h}$ at $50 \mathrm{~V}$ in Trisacetate-EDTA buffer. Gels were stained with $0.5 \mathrm{mg} / \mathrm{L}$ ethidium bromide in MilliQ water (Millipore, Billerica, MA) for $30 \mathrm{~min}$ and visualized under UV light (Gel Doc 1000, Bio-Rad).

\section{Statistical Analysis}

The HRM data were cluster analyzed using $\mathrm{R}$ statistical software (version 2.12.1, R Development Core Team; http://www.r-project.org). The rep-PCR HRM profile data was subjected to alignment using temperature, scaled to $0-100$, and smoothed by a locally weighted scatterplot smoother (LOWESS); first-derivative spectra were calculated for every spectrum. Gelcompare II v6.5 (Applied Maths, Sint-Martens-Latem, Belgium) was used for gel analysis, and rep-PCR patterns were clustered by Pearson correlation. 


\section{RESULTS}

\section{Characterization of Variable Regions by HRM and $16 S$ rRNA Gene Sequencing}

The discriminatory power of the V1 and V3 regions of the $16 \mathrm{~S}$ rRNA gene was tested for Lc. lactis ssp. lactis, Lc. lactis ssp. cremoris, Leuconostoc mesenteroides, and different Lactobacillus species used as reference strains. The HRM profiles of the amplified PCR product from the V1 region were useful in separation of Lc. lactis ssp. lactis and Lc. lactis ssp. cremoris and for separation of the closely related species $L b$. casei/paracasei from $L b$. rhamnosus (Table 2). The melting temperature of the V1 region of Lc. lactis ssp. cremoris and Lc. lactis ssp. lactis showed a clear $\mathrm{T}_{\mathrm{m}}$ difference of $1.4^{\circ} \mathrm{C}$ between these subspecies. The difference between $\mathrm{T}_{\mathrm{m}}$ of the $\mathrm{V} 1$ region of $L b$. rhamnosus and $L b$. casei/paracasei was $3.5^{\circ} \mathrm{C}$. The $\mathrm{V} 1$ region generally showed a lower $\mathrm{T}_{\mathrm{m}}$ than the V3 region because of the length of the amplicon. The analysis of the HRM profiles for the amplified PCR product from the V3 region was more discriminatory compared with that from the $\mathrm{V} 1$ region for the characterization of the Lactobacillus species tested.
The $\mathrm{T}_{\mathrm{m}}$ of the HRM peaks of the $\mathrm{V} 1$ and $\mathrm{V} 3$ regions showed very low standard deviations for the 3 replicates (Table 2), and the HRM profiles were characteristic for each of the reference strains (data not shown). The agarose gel showed single bands corresponding to lengths of 130 and $200 \mathrm{bp}$ for the V1 and V3 regions, respectively. The discrimination at species level by HRM analysis of the V3 region in combination with the V1 region was almost completely achieved. However, some species closely related according to $16 \mathrm{~S}$ rRNA gene sequences were not separated using the HRM approach, such as $L b$. casei from $L b$. paracasei, $L b$. curvatus from $L b$. sakei, and $L b$. plantarum from $L b$. pentosus, as shown by the sequence-based analysis of the $\mathrm{V} 1$ and $\mathrm{V} 3$ regions of the reference strains (Figure 1).

Of the 94 isolates, 62 were identified as Lb. casei/ paracasei, 27 as Lb. plantarum/Lb. pentosus, and 5 as $L b$. curvatus/Lb. sakei by $16 \mathrm{~S}$ rRNA gene sequencing. Comparison of the HRM profiles of the isolates with the HRM profiles of the reference strains for the V3 region showed 3 different groups of peaks (Figure 2), and their $\mathrm{T}_{\mathrm{m}}$ corresponded to the selected representative reference strains (Lb. casei ATCC393, Lb. plantarum ATCC14917, and Lb. curvatus ATCC25601) included

\section{A}

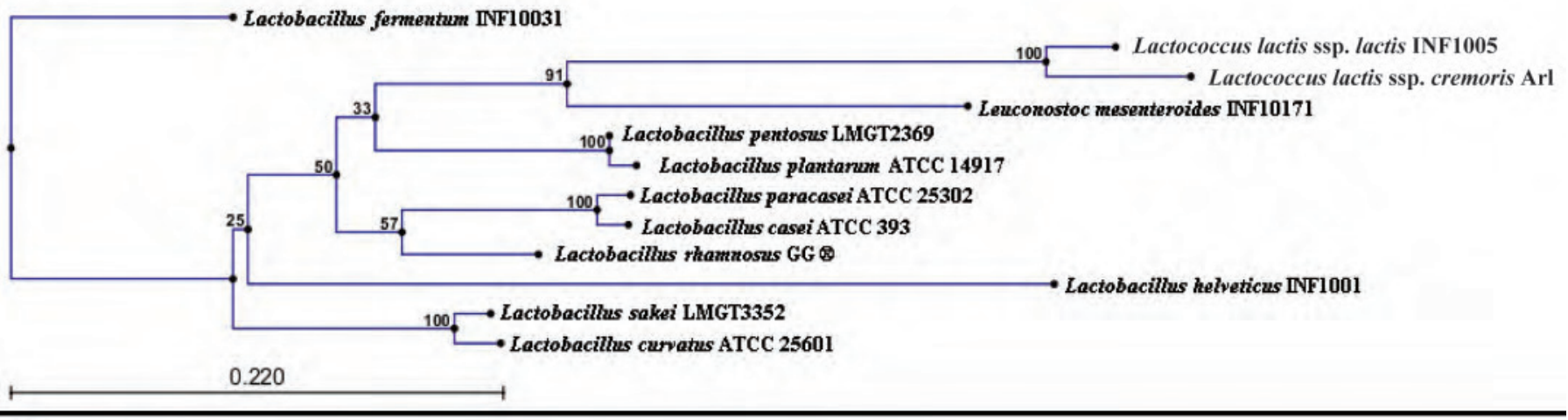

B

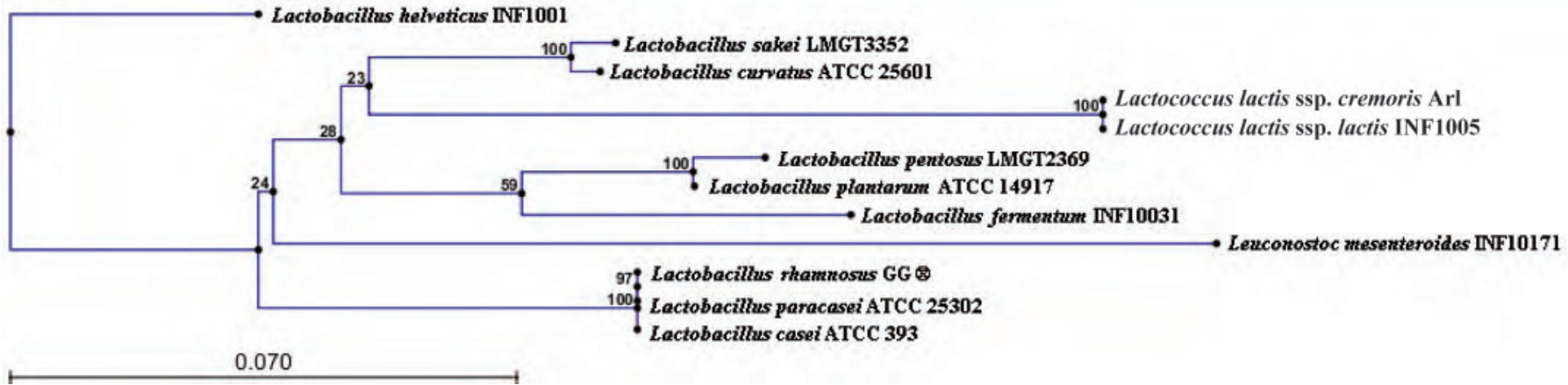

Figure 1. Phylogenetic tree of the reference strains obtained with sequence of the variable regions V1 (A) and V3 (B) of the 16S rRNA gene. The distance unit is shown below the tree and the numbers at the branches indicate the bootstrap confidence value. Color version available in the online PDF. 


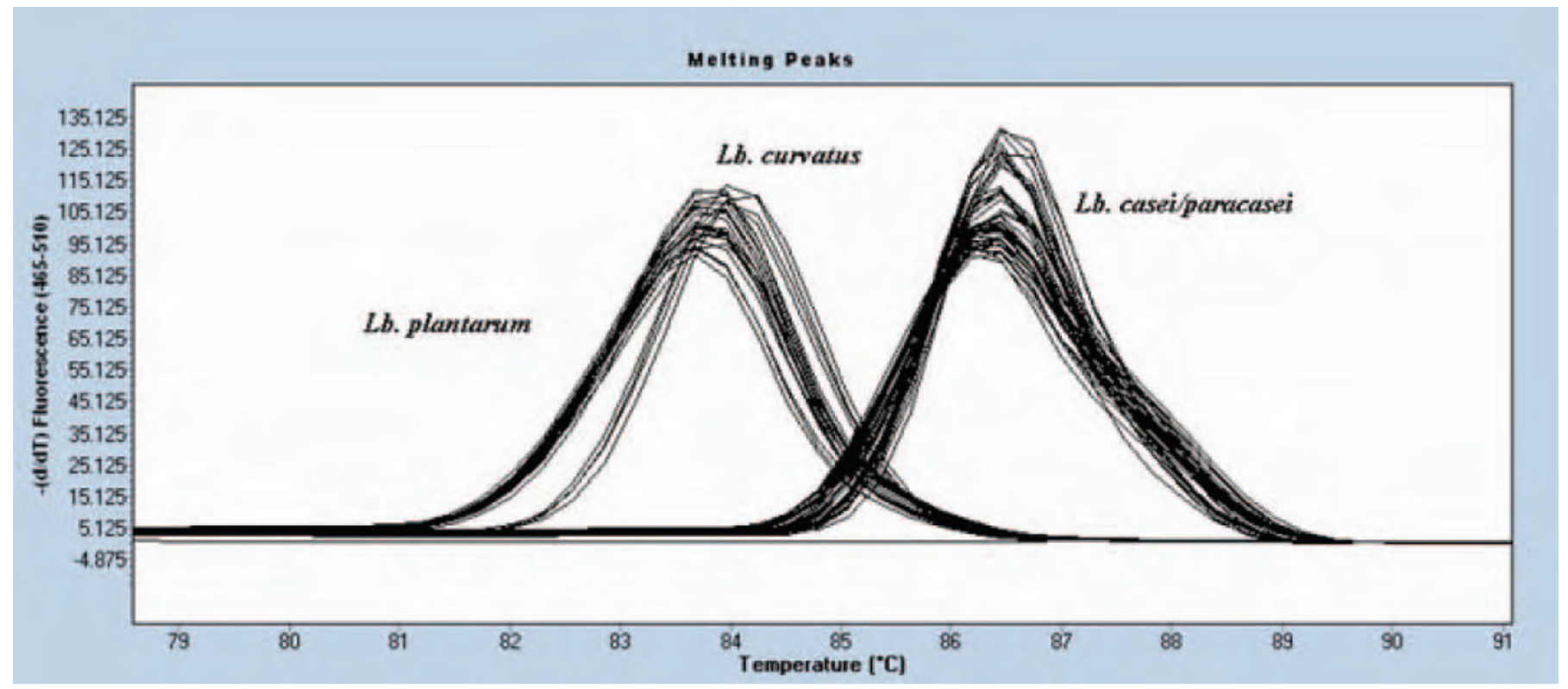

Figure 2. Melting peaks of the variable V3 region of the $16 \mathrm{~S}$ rRNA gene for all 94 cheese isolates and the 3 corresponding reference strains (Lactobacillus casei ATCC393, Lactobacillus plantarum ATCC14917, and Lactobacillus curvatus ATCC25601). Color version available in the online PDF.

in the analysis. In this particular analysis, the $\mathrm{T}_{\mathrm{m}}$ of the $\mathrm{V} 3$ region of the 3 different species was lower compared with the $\mathrm{T}_{\mathrm{m}}$ of the particular runs in Table 2 ; however, the comparison of the HRM profiles of the isolates and the selected reference strains allowed the discrimination.

\section{Fingerprinting Analysis: HRM Method Validation and Characterization of the Cheese Isolates}

To evaluate the repeatability of the HRM method for the rep-PCR-HRM fingerprinting analysis, 10 independent amplifications of $L b$. casei ATCC393, $L b$. paracasei ATCC25302, Lb. plantarum ATCC14917, Lb. curvatus ATCC 25601, and Lb. plantarum INF15D were performed by the use of the $(\mathrm{GTG})_{5}$ primer. All HRM profiles of the 5 selected reference strains were clearly grouped by cluster analysis with more than $97 \%$ similarity for $L b$. casei ATCC393 and Lb. plantarum INF15D and more than $98 \%$ for the 3 other strains (Figure 3).

The rep-PCR fingerprinting analysis was performed for all 94 isolates and the 5 selected representative reference strains by both a gel-based method and HRM profile analysis. The $(\mathrm{GTG})_{5}$ primer band pattern showed from 7 to $20 \mathrm{PCR}$ products on the gel, and the HRM profile showed from 2 to 6 peaks and different curve shapes. All Lb. plantarum cheese isolates showed high similarity and were clustered by both methods (Figure
4, cluster I), whereas 7 and 2 clusters of $L b$. casei/ paracase $i$ and $L b$. curvatus, respectively, were identified by rep-PCR gels. The composition of isolates in the clusters obtained by the rep-PCR gels and the HRM profiles showed the same results for the $L b$. curvatus isolates, whereas 55 out of $64 \mathrm{Lb}$. casei/paracase $i$ isolates (including the ATCC strains) were similarly clustered by the 2 methods (Figure 5 ). Figure 4 shows the cluster dendrogram from the rep-PCR gel cluster analysis and the respective HRM profiles for all clusters. Two cheese isolates and the 3 selected reference strains ( $L b$. casei ATCC393, Lb. paracasei ATCC25302, and Lb. plantarum ATCC14917) were clustered as single clusters by both methods.

\section{DISCUSSION}

In this study, we characterized the NSLAB microflora from Norvegia cheese by an HRM approach combining analysis of the $16 \mathrm{~S}$ rRNA gene and rep-PCR. By comparing HRM profiles of the variable regions of the 16S rRNA gene, the cheese isolates and selected representative reference strains of Norvegia cheese were discriminated. The V1 and V3 regions were chosen in this study and the combination of both profile analyses resulted in better characterization of the reference strains. Interestingly, characterization at subspecies level of Lc. lactis ssp. lactis and Lc. lactis ssp. cremoris was possible even though their V1 regions differ only by 


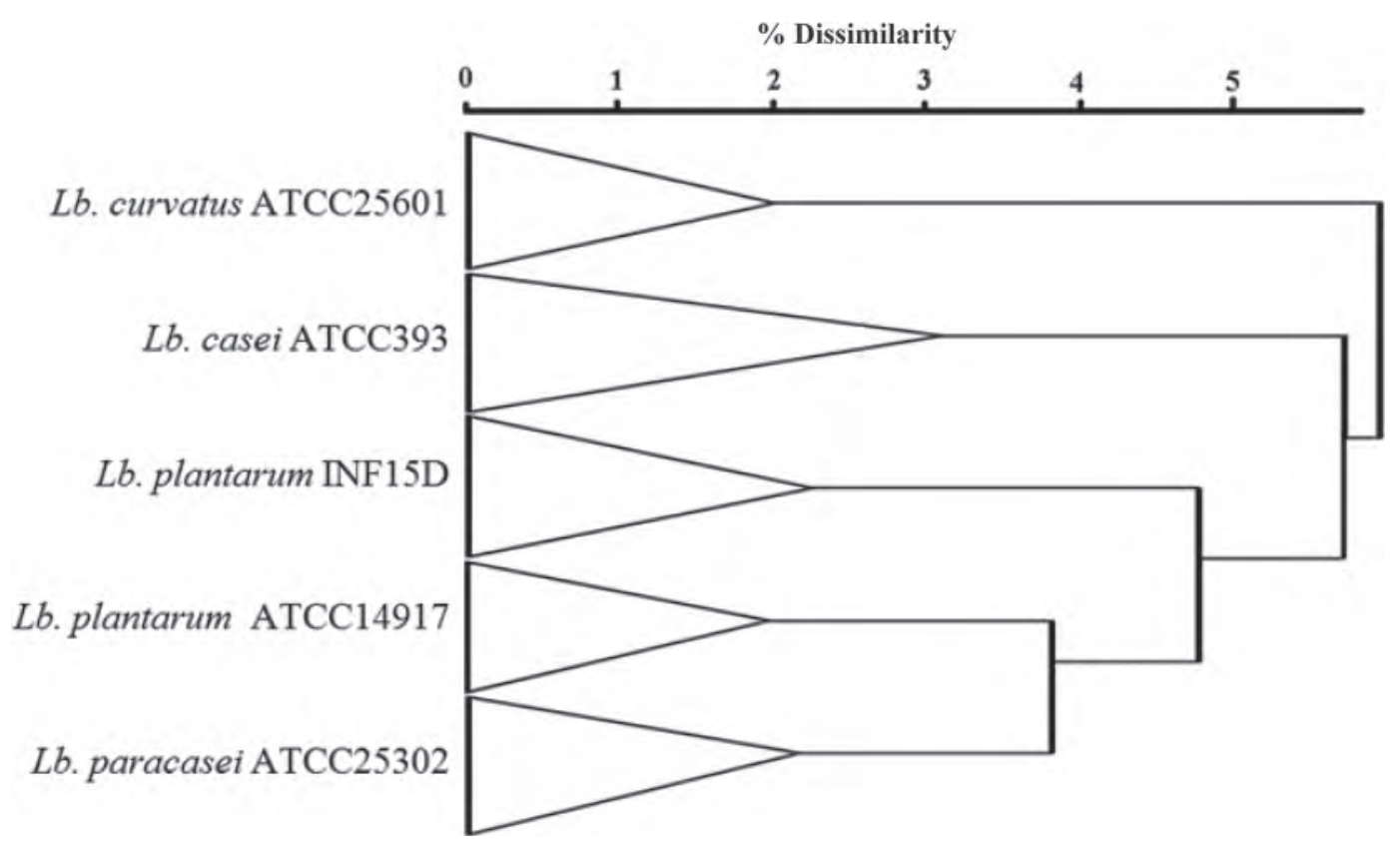

Figure 3. Cluster dendrogram of the 10 independent high-resolution melt runs of the reference strains of Lactobacillus used in the fingerprint analysis.

9 or 10 bp (Ward et al., 1998). By HRM analysis, it was possible to identify the different V1 melting peaks of Lc. lactis ssp. lactis and Lc. lactis ssp. cremoris. The $\mathrm{T}_{\mathrm{m}}$ of the $\mathrm{V} 1$ region showed a difference of $1.4^{\circ} \mathrm{C}$ between the 2 subspecies, whereas the $\mathrm{T}_{\mathrm{m}}$ of the $\mathrm{V} 3$ regions was similar between the subspecies. Lactobacillus casei, $L b$. paracasei, and $L b$. rhamnosus (all belonging to the Lb. casei group) had similar $\mathrm{T}_{\mathrm{m}}$ and melting peaks in the $\mathrm{V} 3$ region; however, $L b$. rhamnosus showed a $3.5^{\circ} \mathrm{C}$ difference in $\mathrm{T}_{\mathrm{m}}$ in the $\mathrm{V} 1$ region compared with $L b$. casei and Lb. paracasei. Kao et al. (2007) showed, by the HRM approach, that it was possible to separate $L b$. casei/paracasei from Lb. rhamnosus based on the $16 \mathrm{~S}$ rRNA sequence by the use of species-specific primers. In the present study, universal primers were used to amplify the V1 region, and the correct characterization of these species was shown. By HRM profile comparison, it was not possible to separate $L b$. casei from $L b$. paracasei. Taxonomic classification of $L b$. casei and Lb. paracasei is still controversial and a final decision regarding reclassification of these species has not been made (Singh et al., 2009). Because of the high similarity of the $16 \mathrm{~S}$ rRNA genes, the $L b$. curvatus and $L b$. plantarum reference strains could not be separated from $L b$. sakei and Lb. pentosus, respectively. By molecular methods, such as random amplification of polymorphic DNA or recA gene sequencing, species of $L b$. curvatus and $L b$. plantarum can be successfully distinguished from their closely related species (Berthier and Ehrlich, 1999; Ghotbi et al., 2011).
The results shown in this study are similar to other studies based on DGGE, where the same variable regions are used to identify LAB by separation in a denaturing gel (Ercolini et al., 2001; Ercolini, 2004; Florez and Mayo, 2006). All 3 species or groups from the Norvegia cheese isolates used in this study were correctly separated into 3 groups (Lb. casei/paracasei, Lb. curvatus/ sakei, and Lb. plantarum/pentosus) by HRM analysis of the V3 region and by $16 \mathrm{~S}$ rRNA gene sequencing. The isolation and characterization of these species in cheese is in accordance with other studies showing the predominance of $L b$. casei/paracasei, Lb. plantarum, and Lb. curvatus in Cheddar and Gouda-type cheese made from pasteurized and microfiltered milk (Jordan and Cogan, 1993; Østlie et al., 2004, 2005).

Although the HRM analysis is precise and reproducible, the use of known reference strains of specific species is required for the characterization of unknown isolates. However, sequencing will still be required to correctly identify unknown isolates that do not match the HRM profiles of known reference strains in the database of the laboratory.

A more in-depth characterization of the cheese isolates was achieved by a combined 16S rRNA-HRM analysis and rep-PCR analysis by HRM. To evaluate the repeatability of the rep-PCR-HRM fingerprinting analysis runs with the $(\mathrm{GTG})_{5}$ primer, 10 independent runs of 5 reference strains were performed. The results showed high similarity between the different runs, with more than $97 \%$ similarity for $L b$. casei ATCC393 and 

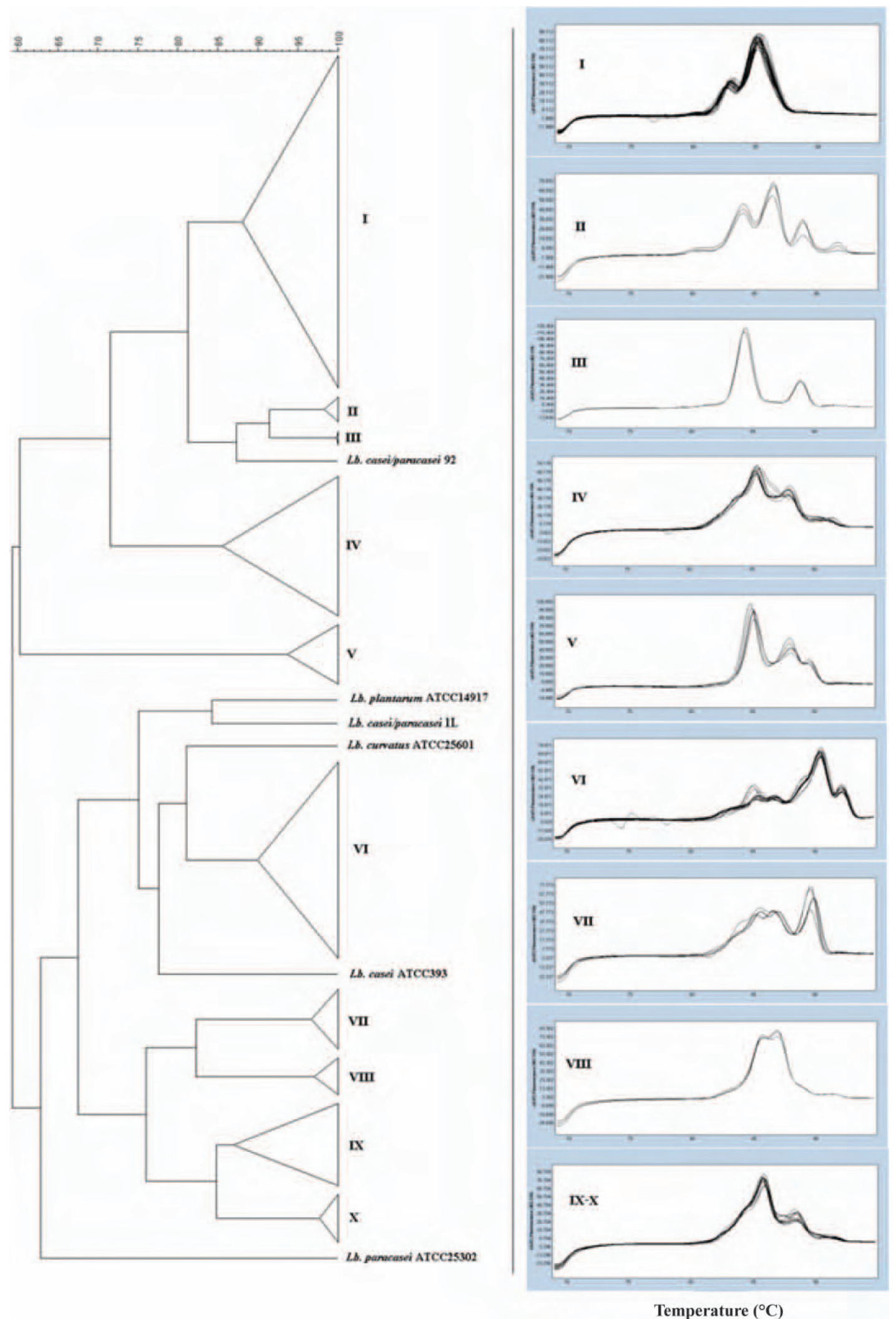

Figure 4. Cluster dendrogram obtained from gel-based repetitive sequence-based PCR (rep-PCR; left) and high-resolution melt (HRM) profiles (right) of the different clusters obtained by gene scanning of HRM-rep-PCR of Lactobacillus strains. Clusters are identified by Roman numerals. Color version available in the online PDF. 


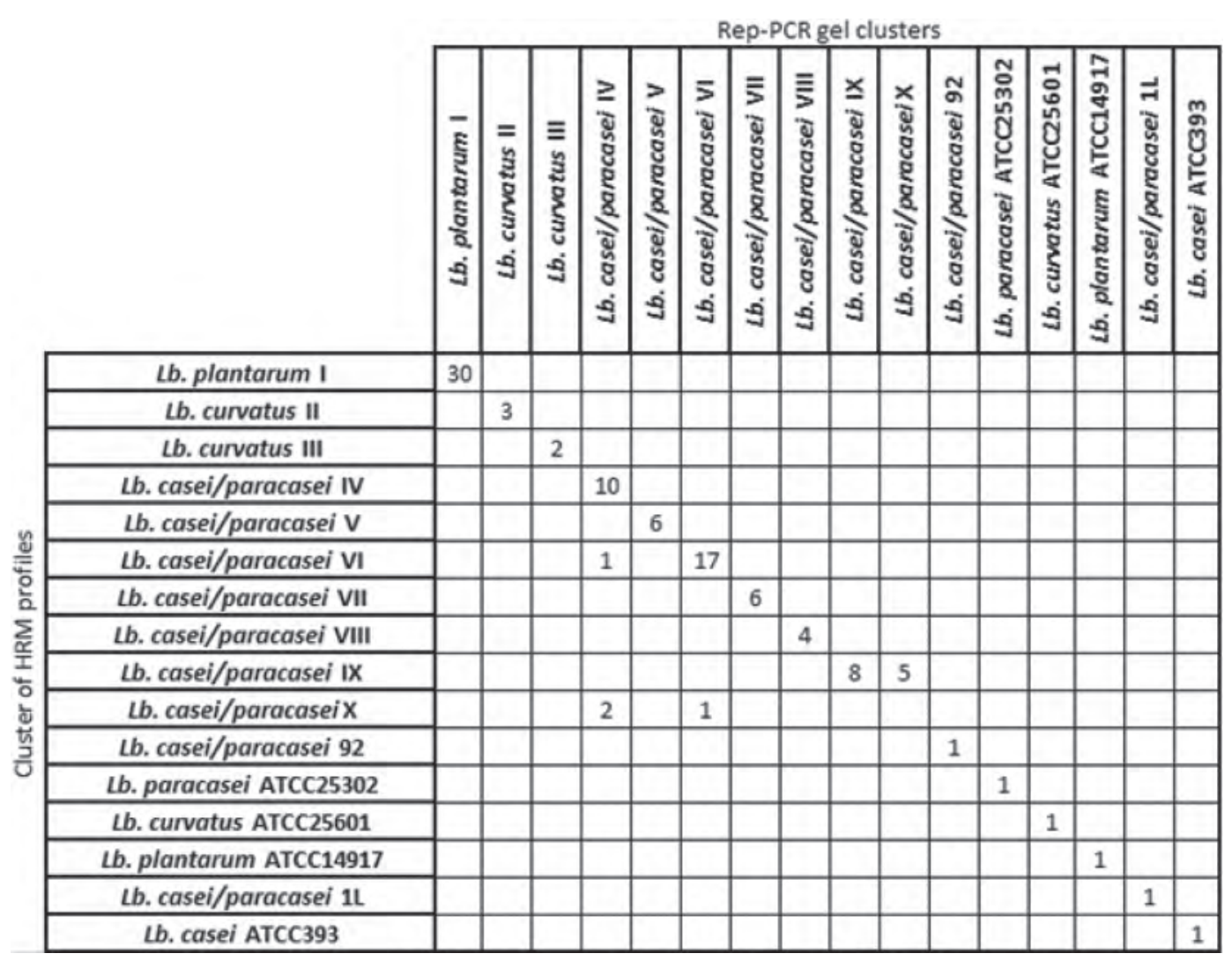

Figure 5. Comparison of clusters identified by the high-resolution melt (HRM) profiles and gel-based repetitive sequence-based PCR (RepPCR). Clusters are identified by Roman numerals. $L b .=$ Lactobacillus.

Lb. plantarum INF15D, and more than $98 \%$ similarity for the other reference strains. The similarity is probably due to the high temperature control performed by the instrument and the reproducibility of the rep-PCR method with the (GTG) 5 primer. Foxman et al. (2005) described the relative repeatability and reproducibility of rep-PCR based on gel analysis as medium to low. However, in this study, almost the same clusters were found for the cheese isolates by both HRM and gelbased rep-PCR analysis. Cluster I (Figure 4) contained all the $L b$. plantarum cheese isolates that showed the same fingerprint patterns and profiles. The Lb. plantarum isolates were isolated from 2 dairies located in different geographical regions in Norway. Lactobacillus plantarum is known to be one of the few species able to survive in cheese for a long time during ripening and this species often becomes the abundant NSLAB together with Lb. casei/paracasei (Fox et al., 1998; Fitzsimons et al., 1999; Antonsson et al., 2003; Østlie et al., 2004). Many phylogroup clusters of Lb. casei/paracasei were found, indicating high variability within Norvegia cheese. The $5 \mathrm{Lb}$. curvatus isolates were isolated from 2 different dairies and rep-PCR analysis by gel and HRM showed separation in 2 clusters according to the origin of the isolates (Figure 4, clusters II and III).

In conclusion, HRM is a promising technique that has been applied rarely in food microbiology. To our knowledge, no previous work has characterized NSLAB from cheese by combining $16 \mathrm{~S}$ rRNA gene and rep-PCR analysis by HRM. Our results illustrate a simple PCR approach for characterization of the NSLAB microflora in cheese. The use of selective agar plating and subculturing to purity may allow the application of this method to other environments, such as other dairy products and fermented food. Furthermore, the number of isolates used in this study suggests that HRM may be used as a rapid, high-throughput screening method. A limitation of the HRM is the inability to discriminate species with high homology to the $16 \mathrm{~S}$ gene sequence because HRM is a sequence-based method. Furthermore, sequencing is still required for samples with melting profiles different from the reference strains included in the analysis. However, HRM is a rapid (20 min), single-step, post-PCR technique without any PCR product handling and without the need for hazardous chemicals. 


\section{ACKNOWLEDGMENTS}

The authors acknowledge the Norwegian Research Council (Oslo), the Norwegian Foundation for Research Levy on Agricultural Products (Oslo), the Norwegian Agricultural Agreement Research Fund, and TINE SA (Oslo, Norway) for financial support. We thank SINTEF (Trondheim, Norway) and TINE SA for the bacterial isolates.

\section{REFERENCES}

Adiguzel, A., H. Ozkan, O. Baris, K. Inan, M. Gulluce, and F. Sahin. 2009. Identification and characterization of thermophilic bacteria isolated from hot springs in Turkey. J. Microbiol. Methods 79:321-328.

Antonsson, M., G. Molin, and Y. Ardo. 2003. Lactobacillus strains isolated from Danbo cheese as adjunct cultures in a cheese model system. Int. J. Food Microbiol. 85:159-169.

Ardö, Y. 2006. Flavour formation by amino acid catabolism. Biotechnol. Adv. 24:238-242.

Beresford, T. P., N. A. Fitzsimons, N. L. Brennan, and T. M. Cogan. 2001. Recent advances in cheese microbiology. Int. Dairy J. 11:259-274.

Berthier, F., and S. D. Ehrlich. 1999. Genetic diversity within Lactobacillus sakei and Lactobacillus curvatus and design of PCR primers for its detection using randomly amplified polymorphic DNA. Int. J. Syst. Bacteriol. 49:997-1007.

Ercolini, D. 2004. PCR-DGGE fingerprinting: Novel strategies for detection of microbes in food. J. Microbiol. Methods 56:297-314.

Ercolini, D., G. Moschetti, G. Blaiotta, and S. Coppola. 2001. Behavior of variable $\mathrm{V} 3$ region from $16 \mathrm{~S}$ rDNA of lactic acid bacteria in denaturing gradient gel electrophoresis. Curr. Microbiol. 42:199-202.

Fitzsimons, N. A., T. M. Cogan, S. Condon, and T. Beresford. 1999. Phenotypic and genotypic characterization of non-starter lactic acid bacteria in mature Cheddar cheese. Appl. Environ. Microbiol. 65:3418-3426.

Florez, A. B., and B. Mayo. 2006. PCR-DGGE as a tool for characterizing dominant microbial populations in the Spanish blue-veined Cabrales cheese. Int. Dairy J. 16:1205-1210.

Fox, P. F., P. L. H. McSweeney, and C. M. Lynch. 1998. Significance of non-starter lactic acid bacteria in Cheddar cheese. Aust. J. Dairy Technol. 53:83-89.

Foxman, B., L. Zhang, J. S. Koopman, S. D. Manning, and C. F. Marrs. 2005. Choosing an appropriate bacterial typing technique for epidemiologic studies. Epidemiol. Perspect. Innov. 2:10.

Gevers, D., G. Huys, and J. Swings. 2001. Applicability of rep-PCR fingerprinting for identification of Lactobacillus species. FEMS Microbiol. Lett. 205:31-36.
Ghotbi, M., S. Soleimanian-Zad, and M. Sheikh-Zeinoddin. 2011. Identification of Lactobacillus pentosus, Lactobacillus paraplantarum and Lactobacillus plantarum in Lighvan cheese with 4 month ripening period by means of recA gene sequence analysis. Afr. J. Biotechnol. 10:1902-1906.

Jordan, K. N., and T. M. Cogan. 1993. Identification and growth of nonstarter lactic-acid bacteria in Irish Cheddar cheese. Ir. J. Agric. Food Res. 32:47-55.

Kao, Y. T., Y. S. Liu, and Y. T. Shyu. 2007. Identification of Lactobacillus spp. in probiotic products by real-time PCR and melting curve analysis. Food Res. Int. 40:71-79.

Klijn, N., A. H. Weerkamp, and W. M. Devos. 1991. Identification of mesophilic lactic-acid bacteria by using polymerase chain reaction-amplified variable regions of $16 \mathrm{~S}$ ribosomal-RNA and specific DNA probes. Appl. Environ. Microbiol. 57:3390-3393.

Lorbeg, P. M., A. C. Majhenic, and I. Rogelj. 2009. Evaluation of different primers for PCR-DGGE analysis of cheese-associated enterococci. J. Dairy Res. 76:265-271.

Østlie, H. M., L. Eliassen, A. Florvaag, and S. Skeie. 2004. Phenotypic and PCR-based characterization of the microflora in Norvegia cheese during ripening. Int. J. Food Microbiol. 94:287-299.

Østlie, H. M., L. Eliassen, A. Florvaag, and S. Skeie. 2005. Phenotypic and PCR-based characterization of the microflora in Prast cheese during ripening. Int. Dairy J. 15:911-920.

Øvreås, L., L. Forney, F. L. Daae, and V. Torsvik. 1997. Distribution of bacterioplankton in meromictic Lake Saelenvannet, as determined by denaturing gradient gel electrophoresis of PCR-amplified gene fragments coding for $16 \mathrm{~S}$ rRNA. Appl. Environ. Microbiol. 63:3367-3373

Patel, V. 2009. High-resolution melt analysis applications. Genet. Eng. Biotechnol. News 29:44-45.

Price, E. P., H. Smith, F. Huygens, and P. M. Giffard. 2007. Highresolution DNA melt curve analysis of the clustered, regularly interspaced short-palindromic-repeat locus of Campylobacter jejuni. Appl. Environ. Microbiol. 73:3431-3436.

Reed, G. H., J. O. Kent, and C. T. Wittwer. 2007. High-resolution DNA melting analysis for simple and efficient molecular diagnostics. Pharmacogenomics 8:597-608.

Settanni, L., and G. Moschetti. 2010. Non-starter lactic acid bacteria used to improve cheese quality and provide health benefits. Food Microbiol. 27:691-697.

Singh, S., P. Goswami, R. Singh, and K. J. Heller. 2009. Application of molecular identification tools for Lactobacillus, with a focus on discrimination between closely related species: A review. J. Food Sci. Technol. 42:448-457.

Versalovic, J., M. Schneider, F. De Bruijn, and J. R. Lupski. 1994. Genomic fingerprinting of bacteria using repetitive sequence-based polymerase chain reaction. Methods Mol. Cell. Biol. 5:25-40.

Ward, L. J. H., J. C. S. Brown, and G. P. Davey. 1998. Two methods for the genetic differentiation of Lactococcus lactis ssp. lactis and cremoris based on differences in the 16S rRNA gene sequence. FEMS Microbiol. Lett. 166:15-20. 